\title{
Estudo da relação entre os aspectos clínicos e anatomopatológicos do carcinoma de células de Merkel
}

Flávia T. França *, Aparecida M. de Moraes.

\section{Resumo}

Este estudo relaciona os aspectos clínicos e histopatológicos do carcinoma de células de Merkel a partir dos casos diagnosticados no Hospital das Clínicas da UNICAMP no período entre 1985 e 2016.

\section{Palavras-chave}

Merkel, carcinoma, histopatológico.

\section{Introdução}

O carcinoma de células de Merkel é um câncer neuroendócrino raro, de pequenas células, com maior prevalência em pessoas idosas, brancas e imunossuprimidas. A localização das lesões está associada às regiões da pele expostas ao sol, como a cabeça, o pescoço e as extremidades. As células do tumor têm alto grau de multiplicação e de disseminação, com comum acometimento sistêmico, sendo que os locais mais frequentes de metástases são fígado, osso e cérebro. Em muitos casos, já existe acometimento de linfonodos regionais e metástases à distância na ocasião do diagnóstico.

O objetivo deste estudo é estabelecer uma relação entre o perfil clínico dos pacientes e dos resultados anatomopatológicos analisados nas lâminas histológicas. Espera-se obter informações das características clínicas e microscópicas que possam propor relação com o prognóstico e a sobrevida no grupo estudado.

\section{Resultados e Discussão}

Os pacientes que tinham antecedente pessoal para neoplasias apresentaram maior incidência de padrão de crescimento tumoral misto (infiltrativo e nodular). Ainda, maior sobrevida foi observada em pacientes com infiltrado inflamatório difuso, e menor sobrevida quando o infiltrado era ausente. Por fim, houve maior e mais precoce mortalidade entre os pacientes com estágio mais avançado do câncer.

Figura 1. Células em atividade mitótica no carcinoma de células de Merkel

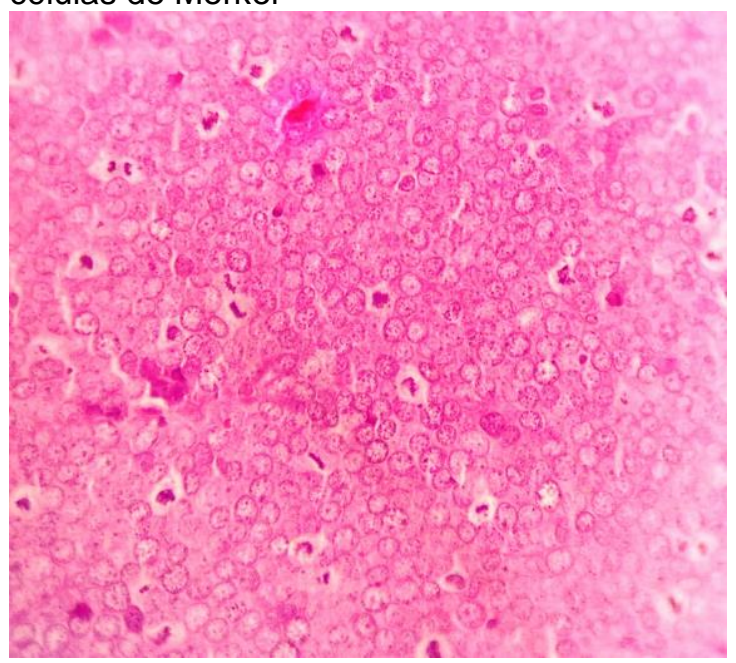

\section{Conclusões}

A partir deste estudo, observamos menor sobrevida quando o câncer é diagnosticado em estágios mais avançados e na ausência de infiltrado inflamatório. $O$ tratamento com radioterapia, quimioterapia, esvaziamento linfático e excisão tumoral não mostrou relação com o tempo de sobrevida.

\section{CNPQ}

\section{Agradecimentos}

1. Almeida MWR, Lopes CC, Junior HLA, Costa LE. Carcinoma de células de Merkel em extremidade inferior. Rev Col Bras Cir 2012; 39: 165-167

2. Becker JC, Kauczok CS, Ugurel S, Eib S, Bröcker EB, Houben R. Merkel cell carcinoma: molecular pathogenesis, clinical features and therapy. $J$ Dtsch Dermatol Ges 2008; 6: 19-709.

3. Cappetta ME, Casas G, Stengel F. Tumor de células de Merkel. Revisión de la Literatura. Arch Argen Dermatol 2009; 59: 227-238.

4. Duprat JP, Landman G, Salvajoli JV, Brechtbühl ER. A review of the epidemiology and treatment of Merkel cell carcinoma. Clinics 2011; 66: 23 1817

5. Eng TY, Boersma MG, Fuller CD, Cavanaugh SX, Valenzuela F, Herman TS.

Treatment of Merkel cell carcinoma. Am J Clin Oncol 2004; 27: 5- 510.

6. Erovic I, Erovic BM. Merkel cell carcinoma: the past, the present, and the future. J Skin Cancer 2013; 2013: 6 páginas.

7. Feng H, Shuda M, Chang Y, Moore PS. Clonal integration of a polyomavirus in human Merkel cell carcinoma. Science 2008; 319: 1096-1100.

8. Heath M, Jaimes N, Lemos B et al. Clinical characteristics of Merkel cell carcinoma at diagnosis in 195 patients: the "AEIOU" features. $J$ Am Ac Dermatol 2008; 58: 375-381.

9. Kaae J, Hansen AV, Biggar RJ, Boyd HA, Moore PS, Wohlfahrt J et al. Merkel cell carcinoma: incidence, mortality, and risk of other cancers. J Natl Cancer Inst, 2010; 102: 793-801.

10. Mello DF, Felix LRM, Rodrigues A, Helene Jr A. Carcinoma das células de Merkel: relato de 2 casos. Rev Bras Cir Plást, 2010; 25: 217-221.

11.Tang CK, Toker C. Trabecular carcinoma of the skin. An ultrastructural study. Cancer 1978; 42: 2311-2321. 